\title{
Prescribing Pattern of Anti-Diabetic Drugs for Type 2 Diabetic Patients in a Tertiary Care Hospital
}

Nazrina $\mathrm{S}^{1}$, Maruf $\mathrm{AA}^{2}$, Rahman W' ${ }^{3}$, Khan $\mathrm{FZ}^{4}$

DOI: https://doi.org/10.3329/jafmc.v14i2.45894

\begin{abstract}
Introduction: Diabetes mellitus (DM), particularly Type 2 DM is now recognized as a major chronic public health problem throughout the world. Different anti-diabetic agents, oral or injectable are used to regulate patients' glycemic status as monotherapy or in combination.
\end{abstract}

Objectives: To observe the prescribingpattern ofanti-diabetic agents and to collect demographic and disease details of type 2 DM patients.

Materials and Methods: This descriptive cross-sectional study was conducted from January to August 2017 in the outpatient department of Border Guard Hospital, Pilkhana; a tertiary level hospital in Dhaka. The study enrolled 172 type 2 diabetic patients purposively on specified criteria. Demographic data,drug prescribing pattern, disease pattern were collected by an interview and from patients' prescriptions.

Results: Among 172 respondents,70 (40.70\%) were male and $102(59.30 \%)$ were female. The mean age of patients was $54.21 \pm 10.09$ years. Eighty seven $(50.58 \%)$ patients were either overweight or obese. Eighty two $(47.67 \%)$ patients had family history of DM. Majority of patients (84.89\%) had duration of diabetes $>5$ years and $84(48.84 \%)$ patients had co-morbidities. Majority of the patients $135(78.49 \%)$ were prescribed oral drugs either alone or in combination. Among them 83 (63.48\%) patients were prescribed oral monotherapy and 52(38.52\%) patients were prescribed oral combination therapy. Metformin was the most prescribed oral anti-diabetic drug as monothearpy $(71.08 \%)$. Among combined anti-diabetic drugsbased on class, metformin+Dipeptidyl peptidase 4 inhibitors(DPP4i) (36.11\%), combination was the most commonly prescribed combination. The findings can lead to select the formulation and combination of anti-diabetic drugs in this part of the world for developing \& marketing a new anti-diabetic drug.

Conclusion: Metformin was the most commonly prescribed drug both as monotherapy as well as combination therapy and monotherapy was predominant over combination therapy.

Key-words: Prescribing pattern, Anti-diabetic drugs, Type 2 DM, Tertiary care hospital.

\section{Introduction}

Diabetes mellitus (DM) is defined as chronic hyperglycemia resulting from either decreased insulin secretion, impaired insulin action or both. Type 2 DM results from the body's ineffective use of insulin. It accounts for approximately $90 \%$ to $95 \%$ of all diagnosed cases of diabetes. DM, particularly type 2 DM is now recognized as a major chronic public health problem throughout the world. Prevalence of diabetes has increased rapidly over the past few decades. In 2014, 422 million people in the world had diabetes, corresponding to a prevalence of $8.5 \%$ among the adult population. According to International Diabetes Federation (IDF), Bangladesh is in 10th position among all countries in the world in 2015 by the number of 7.1 million adults which is set to increase by $91.6 \%$ (13.6 millions) in less than 25 years ${ }^{1}$.

Although extensive resources have been invested to control DM in several developed and developing countries, the management and outcome remain inadequate and Bangladesh as a developing country is not an exception. There is limited data regarding drug use pattern in diabetic patients in Bangladesh. Study related to drug utilization is very important to promote rational drug use. Moreover, irrational prescribing can lead to increased cost of drugs, which often leads to non-adherence ${ }^{2}$. Despite the existence of evidencebased prescribing guidelines, the patterns of drug prescribing are often inappropriate. Studies have suggested the need for evaluation of these patterns in an effort to improve prescribing standards $^{3}$. So this study was conducted to observe the prescribing patternof anti-diabetic agents amongoutpatients of type 2 DM in a tertiary hospital in Dhaka, Bangladesh.

\section{Materials and Methods}

This descriptive cross-sectional study was carried out over 8 months (Januaryto August 2017). The study included 172 type 2 DM patients attending the outpatient department of a tertiary hospital, Bangladesh Border Guard (BGB) hospital, Pilkhana in Dhaka. The patients who were aged between 30 years to 80 years, in optimal mental condition, receiving their medication for at least

1. Lt Col Sayeda Nazrina, MBBS, FCGP, MPhil, Associate Professor of Pharmacology and Therapeutics, AFMC, Dhaka 2. Col Abdullah Al Maruf, MBBS, FCPS, Classified Specialist in Anaesthesiology, CMH, Dhaka 3. Lt Col Wahida Rahman, MBBS, MPhil, Associate Professor of Pharmacology and Therapeutics, AFMC, Dhaka 4. Lt Col Fatema Zerin Khan, MBBS, FCGP, MD, Commanding Officer, 71 Field Ambulance, Jashore. 
6 months from outpatient department, BGB hospital and willing to attend the study were selected for this study. Type 1 DM patients, Gestational diabetic patients, polycystic ovary syndrome (PCOS), disoriented patients and patients who declined to participate were excluded from the study. After getting informed verbal consent from the patients, an interview was conducted by a pretested semi-structured case record form. Demographic data such as age, gender, health related data like BMI, co-morbidities etc. as well as data on prescription were collected with this case record form. Data were analyzed using Microsoft Excel 2010.

\section{Results}

Among the total 172 respondents, 70 (40.70\%) were male and $102(59.30 \%)$ female with male: female ratio of $0.69: 1$. The mean age of the subjects was $54.21 \pm 10.09$ years with a minimum and maximum age of 34 and 74 years respectively. Most of the respondents were in the age group of $50-59$ years $(37.79 \%)$. BMl $\left(\mathrm{kg} / \mathrm{m}^{2}\right)$ of the most respondents (49.42\%) were within normal range of $\mathrm{BMI}\left(\mathrm{kg} / \mathrm{m}^{2}\right)$. Most of the respondents passed higher school certificate (HSC) examination (44.77\%). Majority of the respondents were housewives (52.33\%) followed by retired BGB person (29.65\%), school teachers $(5.82 \%)$, junior commissioned officers $(4.07 \%)$ and others respectively. Total $156(90.70 \%)$ respondents were married. Eighty two (47.67\%) patients had positive family history and most of the patients (48.84\%) had duration of disease more than 10 years (Table-I). Majority of diabetic patients(78.49\%) were prescribed oral drugs followed by both oral and parenteral 20(11.63\%) andonly parenteral $17(9.88 \%)$ (Figure-1). Percentage of prescribed oral anti-diabetic drugs as monotherapy was higher than combination therapy. Among 135 patients 83 $(61.48 \%)$ diabetic patients were prescribed monotherapy and $52(38.52 \%)$ diabetic patients were prescribed combination therapy (Figure-2). Fifty nine (71.08\%) diabetic patients were prescribed Metformin followed by Sulphonyl Urea (SU) (15.66\%) (Table-II). Most prescribed oral combined therapy was Metformin + Sitagliptin (50\%) (Table-III). Furthermore Metformin + Dipeptidyl peptidase 4 inhibitors (DPP4i) combination was most commonly prescribed antidaibetic drugs based on class (36.11\%) (Table-IV). Most of the respondentsreceived short acting insulin $13(76.47 \%$ ) as only parenteral therapy followed by intermediate acting insulin 2(11.76\%) and mixed insulin 2(11.76\%)(Fig-3). About 84 (48.84\%) diabetic patients were with comorbidities andhypertension alone was the commonest 38(45.24\%) (Table-V).
Table-I: Distribution of patients by demographic and health characteristics $(n=172)$

\begin{tabular}{|c|c|c|}
\hline Characteristics & Number & Percentage \\
\hline \multicolumn{3}{|l|}{ Age(in years) } \\
\hline $30-39$ & 18 & 10.47 \\
\hline $40-49$ & 30 & 17.44 \\
\hline $50-59$ & 65 & 37.79 \\
\hline $60-69$ & 49 & 28.49 \\
\hline$\geq 70$ & 10 & 5.81 \\
\hline \multicolumn{3}{|l|}{ Gender } \\
\hline Male & 70 & 40.94 \\
\hline Female & 102 & 59.06 \\
\hline \multicolumn{3}{|l|}{ BMI } \\
\hline Normal range & 85 & 49.42 \\
\hline Overweight & 73 & 42.44 \\
\hline Obese & 14 & 8.14 \\
\hline \multicolumn{3}{|l|}{ Family history } \\
\hline Positive Family history & 82 & 47.67 \\
\hline Negative Family history & 68 & 39.53 \\
\hline Did not know & 22 & 12.80 \\
\hline \multicolumn{3}{|l|}{ Marital status } \\
\hline Married & 156 & 90.70 \\
\hline Others (single, divorcee, widow or widowed) & 16 & 9.30 \\
\hline \multicolumn{3}{|l|}{ Duration of type2 DM } \\
\hline$<5$ years & 26 & 36.11 \\
\hline $5-10$ years & 62 & 36.05 \\
\hline$>10$ years & 84 & 48.84 \\
\hline \multicolumn{3}{|l|}{ Level of education } \\
\hline 10th and below & 10 & 5.81 \\
\hline SSC & 35 & 20.35 \\
\hline HSC & 77 & 44.77 \\
\hline Graduate and above & 50 & 29.07 \\
\hline \multicolumn{3}{|l|}{ Employment status } \\
\hline Housewife & 90 & 52.33 \\
\hline School teacher & 10 & 5.82 \\
\hline Nurse & 2 & 1.16 \\
\hline Sipahi & 2 & 1.16 \\
\hline Noncommissioned officer & 5 & 2.91 \\
\hline Junior commissioned officer & 7 & 4.07 \\
\hline Retired BGB person & 51 & 29.65 \\
\hline
\end{tabular}

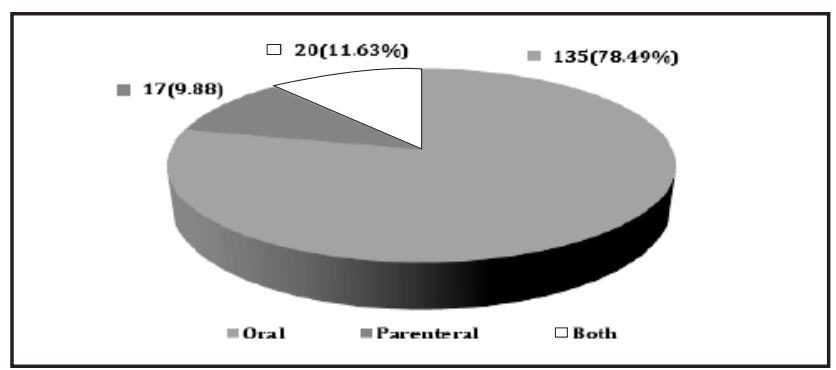

Figure-1: Distribution of patients bydosage formulations of anti-diabetic drugs $(n=172)$

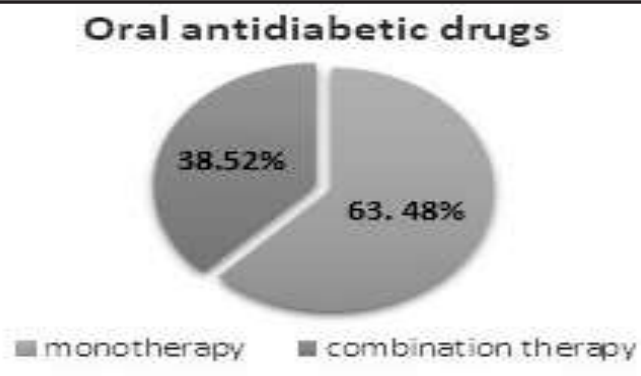

Figure-2: Distribution of oral anti-diabetic agents as monotherapy and combination therapy $(n=135)$ 
Table-II: Prescribing pattern of oral anti-diabetic drugs as monotherapy $(n=83)$

\begin{tabular}{|l|l|c|c|}
\hline \multicolumn{1}{|c|}{ Class of drugs } & \multicolumn{1}{c|}{ Drugs } & Number & Percentage \\
\hline Biguanide & Metformin & 59 & 71.08 \\
\hline Sulphonylurea & Glimeperide & 7 & 8.43 \\
\hline & Gliclazide & 6 & 7.23 \\
\hline Dipeptidyl peptidase 4 inhibitors & Sitagliptin & 10 & 12.05 \\
\hline a glucosidase inhibitor & Acarbose & 1 & 1.21 \\
\hline Total & & 83 & 100 \\
\hline
\end{tabular}

Table-III: Prescribing pattern of oral anti-diabetic drugs based on combination therapy $(n=52)$

\begin{tabular}{|l|c|c|}
\hline Two drug combination therapy & Number & Percentage \\
\hline Metformin + Glimepiride & 16 & 30.77 \\
\hline Metformin + Glibenclamide & 4 & 7.69 \\
\hline Metformin + Glipizide & 5 & 9.62 \\
\hline Metformin + Sitagliptin & 26 & 50 \\
\hline Metformin + Pioglitazone & 1 & 1.92 \\
\hline Total & 52 & 100 \\
\hline
\end{tabular}

Table-IV: Distribution of the combined anti-diabetic drugs prescribed $(n=30)$

\begin{tabular}{|l|c|c|}
\hline \multicolumn{1}{|c|}{ Combined drug } & Number & Percentage \\
\hline Metformin + DPP4i (sitagliptin) & 26 & 36.11 \\
\hline Metformin + glitazone & 1 & 1.39 \\
\hline Metformin + SUs & 25 & 34.72 \\
\hline Metformin+ insulin & 20 & 27.78 \\
\hline Total & 72 & 100 \\
\hline
\end{tabular}

DPP4i=Dipeptidyl peptidase 4 inhibitor

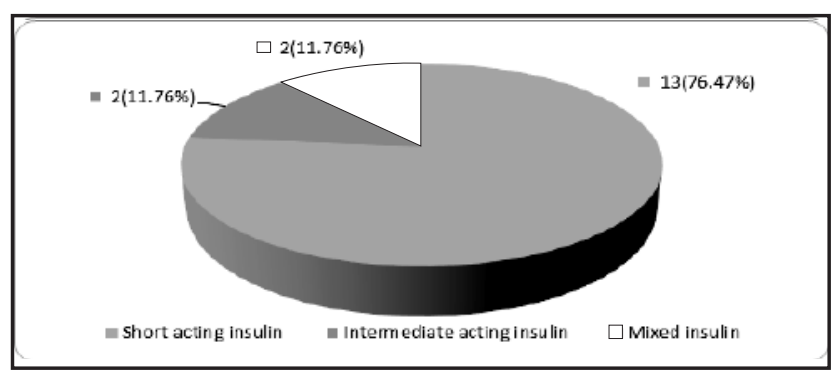

Figure-3: Distribution of different preparations of insulin prescribed as monotherapy $(n=17)$

Table-V: Distribution of co-morbidities associated with type-2 DM $(n=84)$

\begin{tabular}{|l|c|c|}
\hline \multicolumn{1}{|c|}{ Co-morbidity } & Number & Percentage \\
\hline BEP & 3 & 3.57 \\
\hline Cataract & 4 & 4.76 \\
\hline Cataract and hypertension & 5 & 5.96 \\
\hline CKD & 2 & 2.38 \\
\hline COPD & 5 & 5.96 \\
\hline Hypertension & 38 & 45.24 \\
\hline Hypertension with stroke & 4 & 4.76 \\
\hline Hypertension with IHD & 7 & 8.33 \\
\hline Hypertension, obesity & 6 & 7.14 \\
\hline Hypothyroidism & 2 & 2.38 \\
\hline Low back pain & 6 & 7.14 \\
\hline Peptic ulcer disease & 2 & 2.38 \\
\hline Total & 84 & 100 \\
\hline
\end{tabular}

$B E P=$ Benign enlargement of prostate; $C K D$ : Chronic kidney disease;COPD: Chronic obstructive pulmonary disease, IHD: Ischemic heart disease.

\section{Discussion}

This study analyzed the prescribing pattern in type 2 diabetic patients who visited outpatient department of BGB Hospital, Pilkhana. Out of 172 patients, femalespredominated in the study population which is comparable to results of the studies done in Bangladesh and Taiwan ${ }^{3,4}$. Similar studies in India, neither male nor female preponderance was observed ${ }^{5,6}$. This result is dissimilar with the findings of a cohort study observed in the United States. which reported a male preponderance for $\mathrm{DM}^{7}$. The mean age of the patients was $54.21(S D \pm 10.09)$ years with a range between 34 and 74 years. This result was higher than the mean age in a population based study observed by Rahman et al in Bangladesh, (51.4 years) $)^{8}$. On the other hand, it was lower to the studies done in India (59.6 \pm 9.6 years) ${ }^{9}$, Nepal $(56.9 \pm 12.6 \text { years })^{10}$, Hong Kong $(56.5 \pm 12.6 \text { years })^{11}$ and Spain $(60.5 \pm 12.8 \text { years })^{12}$.

The study showed a higher prevalence of diabetes among elderly patients with a highest prevalence in the age group of $50-59$ years (37.79\%). Upadhyay et al ${ }^{10}$ and Venkateswaramurthy et al $^{13}$ from their studies reported higher prevalence of diabetes in elderly patients with a highest prevalence in age group 41-60 years. Greater prevalence in this age group may be due to lack of physical exercise and stressful life condition ${ }^{14}$. In the present study, $50.58 \%$ type-2 diabetic patients were either overweight or obese. Overweight and obese are common health conditions which are increasing globally. Excess weight is associated with an increased incidence of type $2 \mathrm{DM}^{15}$. Several studies in Bangladesh also revealed that, weight gain has a significant association with type-2 diabetes among Bangladeshi populations ${ }^{16-18}$.

This study showed 82 patients (47.67\%) had family history of diabetes which was comparable with the studies done by Venkateswaramurthy et $\mathrm{al}^{13}$, John et $\mathrm{al}^{19}$ and Ramesh et $\mathrm{al}^{20}$. Duration of the disease plays an important role in management of diabetes. A firm glycemic control results in lesser occurrence of complications but complications like retinopathy was related to duration of diabetes but not based on its severity. In this study, majority of patients $(84.89 \%)$ had diabetic duration of $>$ 5yrs. Similar findings were reported by Upadhyay et $\mathrm{al}^{10}$ and Venkateswaramurthy et $\mathrm{al}^{13}$. In contrast, study observed by Ahmed et al showed majority (54\%) has diabetic duration for less than 5 years ${ }^{3}$.

Majority of type 2 DM patients (90.12\%) in this study were prescribed oral drugs either alone $(78.49 \%)$ or in combination (11.63\%). Oral dosage forms can definitely play an important role in improving patient adherence to 
treatment. Metformin alone is most prescribed oral antidiabetic drugs as monotherapy. Unlike sulfonylureas, thiazolidinediones, and insulin, metformin is weight friendly, which makes it a rational choice for obese patients. Furthermore, the management of Type 2 DM can be complicated by hypoglycaemia. Metformin has advantages over insulin and some types of insulin secretagogues; because it rarely causes significant hypoglycemia when used as a monotherapy. As a result, metformin is widely considered an ideal first-line agent for the treatment of Type-2 diabetes. In addition, the cost of metformin is very low, thus making it affordable by the patients in developing countries like Bangladesh. Metformin was found to be the highest prescribed drugs in similar studies ${ }^{10,21,22}$.

Among the sulfonylureas, glimepiride was the most frequently prescribed $(10.84 \%)$ followed by gliclazide $(4.82 \%)$ as monotherapy. Glimepiride is administered as a single daily dose because of its long half-life which improves patient's compliance. It is converted into inactive metabolites by liver which lowers the incidence of hypoglycaemia. Furthermore, there are studies indicating that the blood glucose lowering effect ofglimepiride was not significantly different from metformin. So, it can be considered as a good choice for monotherapy secondary to metformin ${ }^{23}$.

As diabetes progresses, functional decline in beta cells is usually apparent and the need for combination therapy is unavoidable. Therefore, combination modalities have become an integral part of diabetes management. The basic rationale for combination therapy is to provide additive effects with different mechanisms of action and to allow lower doses for disease management. Moreover, the therapeutic approach predominantly depends on the severity of the disease and on physician's perspective. In present study, among oral drug combination therapy, Sitagliptin + Metformin (50\%) was the most commonly prescribed followed by metformin + SUs (46.15\%). Among the second generation SUs, glimepiride was prescribed most $(30.77 \%)$ in combination with Metformin. Several studies showed that a combination of SU with Metformin has been most widely used $\mathrm{d}^{5,9,24}$.

Among combination therapy based on class, Metformin + DPP4i $(36.11 \%)$ were prescribed most followed by Metformin + SUs (34.72\%) and Metformin + Insulin (27.78\%) respectively. In contrast, Kumar et al in their study observed Insulin + Metformin (16.60\%) was the most prescribed antidiabetic combination followed by Glimepiride + Metformin $(10 \%) 25$.

In present study, 84 patients had at least one co-morbidity and hypertension (either alone or with other comorbidities)
$(71.43 \%)$ was the commonest co-morbidity observed. Though commonest, lesser prevalence of hypertension was observed in similar studies by Ahmed et al ${ }^{3}$ (34.50\%), Kannan et $\mathrm{al}^{5}(33.33 \%)$, John LJ et al ${ }^{19}(57.80 \%)$, Joshi et $\mathrm{al}^{21}(67.50 \%)$. High prevalence of hypertension was associated with increased stiffness of large arteries, which often precedes macrovascular events.

\section{References}

1. International Diabetes Federation. IDF Diabetes Atlas. 7th ed. Brussels: International Diabetes Federation, 2015.

2. Kennedy J, Erb C. Prescription noncompliance due to cost among adults with disabilities in the United States. Am J Public Health 2002; 92(7):1120-4.

3. Ahmed Z, Hafez MA, Bari MA, Akhter J. Pattern of anti-diabetic drugs prescribed in a tertiary care hospital of Bangladesh. Int J Basic Clin Pharmacol 2016; 5(1):6-12.

4. Tseng $\mathrm{CH}$. The Epidemiologic Transition of Diabetes Mellitus in Taiwan: Implications for Reversal of Female Preponderance from a National Cohort. The Open Diabetes Journal 2009; 2:18-23.

5. Kannan, Arshad, Kumar S. A study on drug utilization of oral hypoglycemic agents in type-2 diabetic patients. Asian J Pharm Clin Res 2011; 4:60-4.

6. Dave DJ, Dikshit RK, Gandhi AM. Utilization of some newer oral antidiabetic agents in a tertiary care hospital. Natl J Physiol Pharm Pharmacol 2012; 2(2):146-51.

7. Boccuzzi SJ, Wogen J, Fox J, Sung JCY, Shah AB, Kim J. Utilization of Oral Hypoglycemic Agents in a Drug-Insured U.S. Population. Diabetes Care 2001; 24(8):1411-5.

8. Rahman MS, Akter S, Abe SK et al. Awareness, Treatment, and Control of Diabetes in Bangladesh: A Nationwide Population-Based Study. PLoS ONE 2015; 10(2):e0118365.

9. Haghighatpanah M, Thunga G, Jha A et al. Study on prescribing pattern of anti-diabetic drugs among type-2 diabetes patients with complication in south indian teaching hospital. Asian J Pharm Clin Res 2016; 9(1):194-7.

10. Upadhyay DK, Palaian S, Shankar RP et al. Prescribing pattern in diabetic outpatients in a tertiary care teaching hospital in Nepal. J Clin Diagn Res 2007; 3:248-55.

11. Lau GSN, Chan JCN, Chu PLM et al. Use of antidiabetic and antihypertensive drugs in hospital and outpatient settings in Hong Kong. Ann Pharmacother 1996; 30:232-7.

12. Perez RF, Caballero PG.Pattern of prescription of hypoglycemic drugs in Gran Canaria (Canary Islands, Spain) and estimation of the prevalence of diabetes mellitus. Diabet Metab 2005; 31(5):457-62.

13. Venkateswaramurthy N, ShajeemMS, Sambathkumar R et al. Prescribing pattern of antidiabetic drugs in type-2 diabetic patients. IJPSR 2016; 7(11):4550-5. 
14. Vengurlekar S, Patidar P, Bafna R et al. Prescribing pattern of antidiabetic drugs in indore city hospital. Indian J Pharm Sci 2008; 70(5):637-40.

15. Burton BT, Foster WR. Health implications of obesity: An NIH Consensus Development Conference. J Am Diet Assoc 1985; 85(9):1117-21.

16. Rahim MA, Hussain A, Azad Khan AK et al. Rising prevalence of type-2 diabetes in rural Bangladesh: A population based study. Diabetes Res Clin Pract 2007; 77(2):300-5.

17. Ahasan NHAM, Islam Z, Alam B et al. Prevalence and risk factors of type-2 diabetes mellitus among secretariat employees of Bangladesh. J Med 2011; 12(2):125.

18. Chowdhury MAB, Uddin MJ, Khan HMR et al. Type-2 diabetes and its correlates among adults in Bangladesh: A population based study. BMC Public Health 2015; 15:1070.

19. John LJ, Arifulla M, Sreedharan $\mathrm{J}$ et al. Age and gender based utilization pattern of antidiabetic drugs in Ajman, UAE. Malaysian J Pharm Sci 2012; 10(1):79-85.
20. Ramesh R, Kumar SV, Gopinath S et al. Diabetic knowledge of rural community and drug utilization pattern in a tertiary care hosptial. Int J of Pharm \& Life Sci 2011; 2(1):531-5.

21. Joshi H, Mary R, Padil GM et al. Investigation of In-Patient Prescribing Patterns of Oral Antidiabetic Drugs in a Tertiary Care Teaching Hospital. Afr J Pharmacol Ther 2013; 2(2):54-5.

22. Kannan A, Kumar S. A study on drug utilization of oral hypoglycemic agents in type-2 diabetic patients. Asian J Pharm Clin 2011; 4(4):60-4.

23. Zhu H, Zhu S, Zhang Xet al. Comparative efficacy of glimepiride and metformin in mono-therapy of type-2 diabetes mellitus: Meta-analysis of randomized controlled trials. Diabetol Metab Syndr 2013; 5(1):70.

24. Hermann LS, Schersten B, Bitzen PO et al. Therapeutics comparison of metformin and sulphonylurea alone and in combinations. A double blind controlled study. Diabetes Care 1994; 17:1100-9.

25. Kumar KS, Sreeramya G, Krishna KM, et al. Drug use pattern study of antidiabetics in type 2 diabetes mellitus at a tertiary care hospital in Tenali, Andhra Pradesh. Int J Inv Pharm Sci 2013; 1:162-6. 